\title{
DOI
}

10.21608/zumj.2021.88829.2308

ORIGINAL ARTICLE

\section{Salusin- $\beta$ in Patients with Subclinical Hypothyroidism and Low to Moderate Cardiovascular Disease Risk}

\author{
Hassan Mahmoud Hassanin ${ }^{*}$, Hala Gouda Abomandour ${ }^{2}$, Ahmad Mahmoud Hassaneen ${ }^{3,4}$, Alaa Ahmed \\ Farag $^{I}$, Amany Mohyeldin Sediq ${ }^{3}$ \\ ${ }^{1}$ Internal Medicine Department, Faculty of Medicine, Zagazig University, Zagazig, Egypt. \\ ${ }^{2}$ Cardiology Department, Faculty of Medicine, Zagazig University, Zagazig, Egypt \\ ${ }^{3}$ Clinical Pathology Department, Faculty of Medicine, Zagazig University, Zagazig, Egypt \\ ${ }^{4}$ Sulaiman AlRajhi University, Al Bukayriyah, Saudi Arabia
}

"Corresponding author:
Hassan Mahmoud
Hassanin*
Internal Medicine
Department, Faculty of
Medicine, Zagazig
University, Zagazig,
Egypt.
Email:
Drhassan_h99@yahoo.com

Submit Date 2021-08-04

Revise Date 2022-01-26

Accept Date 2021-08-17

\begin{abstract}
Background:Because Subclinical hypothyroidism may be a risk factor for cardiovascular disease, we aimed to measure the level of salusin- $\beta$ which is a new biomarker for predicting atherosclerotic cardiovascular diseases (CVD) in those patients.

Methods:57 subclinical hypothyroid patients were compared with a control group of 60 euthyroid subjects whose age and sex were matched to the patient group. Both groups have low to moderate 10 -year risk of fatal CVD. We studied the serum level of salusin- $\beta$ in the selected group of SC hypothyroid patients to find out if it can be used as an indicator of the cardiovascular adverse effects in them. We also studied the association between salusin- $\beta$ levels and thyroid stimulating hormone (TSH) level, thyroid Ab, and individual's risk of CVD.
\end{abstract}

Results : Salusin- $\beta$ was higher in the SC hypothyroidism group with a significant difference $(\mathrm{p}=0.001)$. TSH, FT4, diastolic BP and triglycerides showed a significant difference between the two groups. Systolic BP, total cholesterol, smoking, and SCORE showed no significant difference between the two groups. There was a highly +ve correlation with TSH level in the SC hypothyroid group. Conclusions:The elevated salusin- $\beta$ level supports the opinion that SC

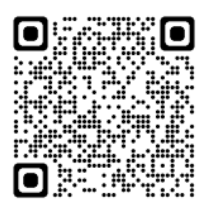
hypothyroidism has a cardiovascular risk and can support treatment of these cases whose TSH < $10 \mathrm{mIU} / \mathrm{l}$.

keywords: Salusin- $\beta$; Subclinical hypothyroidism; Cardiovascular disease risk

\section{INTRODUCTION}

ubclinical hypothyroidism (SC hypothyroidism) exists when serum thyroid hormone levels are within the reference interval, but serum thyrotropin level is higher than the upper reference limit of the studied population [1]. The diagnosis of SC hypothyroidism is a biochemical one based on the result of thyroid function testing only. It affects about $10 \%$ of iodine-sufficient populations and is more prevalent in females and elderly [2].

In a meta-analysis of 15 studies, an increased prevalence of coronary heart diseases (CHD) in SC hypothyroidism in comparison with euthyroid subjects has been observed but the significance was limited to subjects younger than 65 years [3]. Meanwhile, the cardiovascular Health Study (included 3233 subjects), demonstrated no increased incidence of cardiovascular events in subjects with
SC hypothyroidism [4]. Despite various populationbased studies were conducted to assess the association between SC hypothyroidism and cardiovascular diseases (CVD), the existing data are still conflictive.

The definition of ten-year cardiovascular risk was developed as a collaborative work between multiple international organizations. It is defined as "the risk of developing a first atherosclerotic cardiovascular (ASCVD) event, defined as nonfatal myocardial infarction or CHD death or fatal or nonfatal stroke, over a 10-year period among people free from ASCVD at the beginning of the period". The Systematic Coronary Risk Estimation (SCORE) system was developed to calculate the ten-year cardiovascular risk [5].

Salusins are a new class of vasoactive peptides [6]. Salusin- $\beta$ is localized to the neuroendocrine system 
in the brain, throughout systemic endocrine cells and in certain hematopoietic cells, such as macrophages [7]. In vitro, salusin- $\beta$ stimulates the release of oxytocin and arginine-vasopressin from the rat neurohypophysis [8]. Through stimulating the expression of monocyte chemoattractant protein-1, interleukin-1 beta and vascular cell adhesion molecule- 1 in endothelial cells, salusin- $\beta$ is believed to have a role in the formation and progression of atherosclerosis [9]. It also induces bradycardia, rapid and temporary hypotension, and cardiac dysfunction by a cholinergic mechanism [10].

We studied the serum level of salusin- $\beta$ in a selected group of SC hypothyroid patients to find out if it can be used as an indicator of the cardiovascular adverse effects in them. We also studied the association between salusin- $\beta$ levels and TSH level, thyroid A.B. , and individual's risk of CVD. To our best knowledge, this is the first clinical study that studied the level of salusin- $\beta$ in SC hypothyroid patients.

\section{METHODS}

This is a cross-sectional study. Informed consents were obtained from the patients or their legal medical representative before being included in the study. The study was approved by Zagazig Medical Institutional Review board (IRB\#:6865) and was in accordance with the ethical standards of 1964 Helsinki declaration.

The study included 57 SC hypothyroidism patients with low to moderate CVD risk (SCORE < 5) recruited from Endocrinology Clinic, and 60 euthyroid subject as a control group. Patients and control groups were age and sex matched. Exclusion criteria included patients with cardiovascular disease, diabetes (type 1 or 2), chronic kidney disease, familial hypercholesterolemia, or very high levels of individual risk factors (e.g. resistant hypertension or morbid obesity) where no risk estimation models are needed as they all need active management of risk factors ,so SCORE is not applied to estimate their risk level. Also, SC hypothyroidism patients on thyroid medication were excluded.

For all subjects, venous blood samples were collected on 2 plain tubes for serum separation, one used for immediate measurement of TSH, FT4, antiTPO and anti-Tg (electrochemiluminescence assay) using Cobas 8000/e601 auto analyzer (Roche diagnostics, Germany). SC hypothyroidism was diagnosed by TSH > $4.0 \mathrm{mIU} / \mathrm{l}$ and normal FT4 (12$22 \mathrm{pmol} / \mathrm{l})$. Anti-bodies against thyroid peroxidase (anti-TPO) and anti-bodies against thyroglobulin (anti-Tg) were considered positive if one/both is more than $34 \mathrm{IU} / \mathrm{ml}$ and $115 \mathrm{IU} / \mathrm{ml}$, respectively.

The separated serum from the 2 nd tube was frozen at $-80^{\circ} \mathrm{C}$ until salusin- $\beta$ quantification using competitive enzyme-linked immunosorbent assay kits (MyBioSource, San Diego, USA).

\section{STATISTICAL ANALYSIS}

Statistical analysis was performed using IBM SPSS Statistics version 25.0 (IBM Corp, Armonk, NY, USA). We used the Kolmogorov-Smirnov test for normality. All parameters were not normally distributed and expressed as median ( $\min -\max )$ and compared using Mann-Whitney U test. Categorial data was expressed as (number \& percentage) and compared using Chi- Square test. Spearman's rank correlation analysis was used to study the association between non-normally distributed numerical variables. Statistical significance was set at $\mathrm{p}<0.05$. Sequential multiple regression analysis was run using TSH and LDL-C as independent variables and salusin- $\beta$ as dependent variable after correction for possible effect of age and gender by excluding cases pairwise.

\section{RESULTS}

The demographic, clinical and biochemical data of the enrolled patients and control subjects are summarized in (Table 1). Among the studied parameters, diastolic blood pressure (DBP), triglycerides, HDL-c, TSH, FT4, percentage of cases with +ve thyroid Abs, and salusin- $\beta$ were significantly different between the studied groups $(p=0.03,0.005,<0.001,<0.001,<0.001,0.005$, and 0.001 respectively). Studying the association between salusin- $\beta$ concentration and other parameters in each group showed that in the SC hypothyroid group, a positive association exists between salusin- $\beta$ and TSH $(\mathrm{r}=0.437, p=0.001)$ and LDL-c ( $\mathrm{r}=0.283, p=0.033)$ level. Table (2).

Multiple regression analysis showed that TSH and LDL-C are a significant predictors of salusin- $\beta$, $F(4,52)=5.090, \quad P=0.002, \quad R^{2}=0.281, \quad$ adjusted $R 2=0.226$. Only $\mathrm{TSH}$ added significantly to the prediction $(\mathrm{B}=4.688, \quad \mathrm{SE}=1.298, \quad \beta=0.442$, $P=0.001)$. Whereas LDL-C didn't have the same effect $(\mathrm{B}=0.122, \mathrm{SE}=0.069, \beta=0.229, P=0.084)$. 
Table 1: Demographic, clinical and biochemical characteristics of the study population

\begin{tabular}{|c|c|c|c|}
\hline & Euthyroid (60) & SC hypothyroidism (57) & $p$ \\
\hline Age (year) & $47(38-57)$ & $46(27-56)$ & 0.254 \\
\hline $\begin{array}{ll}\text { Gender: } & \\
& \mathrm{F}: \\
\mathrm{M}:\end{array}$ & $\begin{array}{l}39(65) \\
21(35)\end{array}$ & $\begin{array}{c}40(70.2) \\
17(29.8)\end{array}$ & 0.552 \\
\hline $\begin{array}{l}\text { Smoking: } \\
\text { Smoker : } \\
\text { Non-smoker : }\end{array}$ & $\begin{array}{l}13(21.7) \\
47(78.3)\end{array}$ & $\begin{array}{l}13(22.8) \\
44(77.2)\end{array}$ & 0.883 \\
\hline Systolic BP & $140(115-160)$ & $136(115-157)$ & 0.133 \\
\hline Diastolic BP & $82(70-92)$ & $85(72-98)$ & $\mathbf{0 . 0 3}$ \\
\hline SCORE: & $1(0-4)$ & $1(0-4)$ & 0.661 \\
\hline Total cholesterol (mg/dl) & $5.3(3.8-6.7)$ & $5.4(3.6-7.1)$ & 0.156 \\
\hline $\mathrm{TG}(\mathrm{mg} / \mathrm{dl})$ & $105(75-125)$ & $113(75-134)$ & 0.005 \\
\hline HDL-c & $43(38-48)$ & $37(33-43)$ & $<0.001$ \\
\hline LDL-c & $140.6(89.8-196.3)$ & $150.6(79.2-217.4)$ & 0.054 \\
\hline TSH (mIU/l) & $2.4(1.5-3.3)$ & $7.7(4.411)$ & $<0.001$ \\
\hline FT4 (pmol/L) & $18.8(14.9-21.7)$ & $14.6(12.4-19)$ & $<0.001$ \\
\hline $\begin{array}{l}\text { Thyroid Ab: } \\
\text { positive: } \\
\text { Negative: }\end{array}$ & $\begin{array}{c}7(11.7) \\
53(88.3)\end{array}$ & $\begin{array}{l}19(33.3) \\
38(66.7)\end{array}$ & 0.005 \\
\hline Salusin- $\beta(\mathrm{pg} / \mathrm{ml})$ & $200.5(160-240)$ & $215(180-247)$ & 0.001 \\
\hline
\end{tabular}

SC hypothyroidism: subclinical hypothyroidism; F:female; M:male; BP: blood pressure; SCORE: Systematic coronary risk evaluation; TG: triglycerides; HDL-c: high density lipoprotein-cholesterol; LDL-c: low density lipoprotein-cholesterol; TSH: Thyrotropin hormone; FT4: free tetraiodothyronine. Data are presented as median (min- max) or $\mathrm{n}(\%)$. Bold values are significant at $p<0.05$.

Table 2: Association between salusin- $\beta$ level and other parameters in each group.

\begin{tabular}{|c|c|c|c|c|}
\hline & \multicolumn{2}{|c|}{ Salusin- $\beta$ in euthyroid } & \multicolumn{2}{|c|}{ Salusin- $\beta$ in SC hypothyroism } \\
\hline & $\mathrm{r}$ & $p$ & $\mathrm{r}$ & $p$ \\
\hline Systolic BP & -0.181 & 0.166 & 0.117 & 0.386 \\
\hline Diastolic BP & -0.02 & 0.879 & -0.037 & 0.784 \\
\hline SCORE & -0.056 & 0.668 & 0.094 & 0.487 \\
\hline Total cholesterol & -0.031 & 0.811 & 0.276 & 0.038 \\
\hline TG & -0.026 & 0.844 & 0.061 & 0.654 \\
\hline HDL-c & 0.014 & 0.917 & -0.117 & 0.388 \\
\hline LDL-c & -0.024 & 0.855 & 0.283 & 0.033 \\
\hline TSH & -0.015 & 0.909 & 0.437 & 0.001 \\
\hline FT4 & 0.106 & 0.418 & -0.015 & 0.909 \\
\hline
\end{tabular}

SC hypothyroidism: subclinical hypothyroidism; BP: blood pressure; SCORE: Systematic coronary risk evaluation; TG: triglycerides; HDL-c: high density lipoprotein-cholesterol; LDL-c: low density lipoproteincholesterol; TSH: Thyrotropin hormone; FT4: free tetraiodothyronine. Bold values are significant at $p<0.05$.

\section{DISCUSSION}

Serum TSH is the first-line diagnostic test in thyroid disease. Both overt and subclinical hypothyroidism have a raised TSH level, but free T4 \& 33 are normal in the latter with mild or no symptoms. The reference range for TSH levels in thyroid disease-free individuals is $0.4-4.0 \mathrm{mIU} / 1$. SC hypothyroidism is defined when raised serum TSH coexists with a normal free $\mathrm{T} 4$ and $\mathrm{T} 3$ [11]. As expected, in the 
present study the difference in TSH \& FT4 was highly significant between the studied groups.

We found no significant difference in systolic blood pressure (SBP), but (DBP) was higher in the SC hypothyroid group. In one community-based study, there was no significant difference in mean SBP, DBP and the prevalence of hypertension between SC hypothyroid patients and controls [12]. By contrast, another study showed that high normal TSH levels were associated with a modest increase of blood pressure [13].

In our study, serum total cholesterol was higher in the SC hypothyroid group without statistical significance, while triglycerides (TGs) showed a significant difference $(p=0.005)$. Several studies have linked SC hypothyroid and lipid profile; however, the results are conflicting. In a metaanalysis study included fifteen studies, most results showed elevated serum TGs levels in SC hypothyroid patients in comparison with euthyroid individuals and only 2 studies showed lower levels with no statistical significance, and that the overall serum TGs level in SC hypothyroid groups was significantly higher than in euthyroid group [14]. So, these non-decisive results impede the use of lipid profile in risk stratification of SC hypothyroid individuals.

Overt hypothyroidism has been linked with a higher risk for atherosclerotic heart disease as indicated by dyslipidemia and hypertension. Hypothyroidism can cause low cardiac output, decreased arterial compliance, elevated systemic vascular resistance, and atherosclerosis [15].

A meta-analysis of observational studies found a clear difference in the association between subclinical hypothyroidism and cardiovascular risk in various age groups, with significant association in patients younger than 65 years $(\mathrm{OR} 1.37$; $95 \% \mathrm{CI}$ $1.04-1.79)$ but not in older individuals $[16,17]$. The risk of cardiovascular mortality was increased in some studies [18-21], but not in others [16,22-24]. So, the evidence of association between cardiovascular risk and SC hypothyroidism is less obvious than that with overt hypothyroidism.

Salusins are a class of bioactive peptides that have a proinflammatory action on vascular endothelial cells, promote nuclear factor- $\mathrm{kB}$ signals, and helps the formation of macrophage foam cell. They have a fast bradycardiac and hypotensive effects, and significant effects on the pathogenesis of atherosclerosis. So, they gained attention in atherosclerotic diseases pathogenesis [25]. Indeed, salusin- $\beta$ stimulates the release of oxytocin and arginine-vasopressin in rats in vitro [8].

Salusin- $\beta$ was detected in coronary atherosclerotic plaques, vascular smooth muscle cells and fibroblasts. These findings indicate that salusin- $\beta$ plays several roles in atherogenesis [26]. Sato and his colleagues stated that the level of salusin- $\beta$ in blood and cardiovascular tissues can be used as a tool for predicting atherosclerotic cardiovascular diseases [27]. Two recent studies indicated that salusin- $\beta$ plays a role in pathogenesis of Slow Coronary Flow (SCF) which is a distinct coronary micro vascular syndrome characterized by recurrent chest pain [28.29].

Measuring the level of serum salusin- $\beta$ in our subjects' groups showed a significant difference in salusin- $\beta$ between both groups $(p=0.001)$, with a higher level in the SC hypothyroid group. In SC hypothyroid group, salusin- $\beta$ had a positive association with TSH and LDL-c.

These findings support the theory of cardiovascular effect of SC hypothyroid, an area which still unclear. Measuring salusin- $\beta$ level in the SC hypothyroid patients with low to moderate SCORE may help to detect cardiovascular effects of hypothyroidism much earlier than expected.

Weather these findings support treatment of SC hypothyroid especially with TSH $<10 \mathrm{mIU} / \mathrm{l}$ or not, is not an easy to answer question. To our best of knowledge, no other studies on salusin- $\beta$ in SC hypothyroid patients have been done. In one study [ 30], the level of salusin alpha, which is a cardio protective peptide, was found to be higher in patients with overt and SC hypothyroidism than in controls but salusin- $\beta$ was not measured.

We recognize some limitations in our study. One limitation is the modest sample size. Still, this is the first study of its kind, little data is available for comparing results. As a single-center study, further studies are recommended on a larger scale or a multicenter level to confirm these results. Prospective study and follow up of SC hypothyroid patients for detection of $\mathrm{CV}$ complication may reveals more facts about role of salusin- $\beta$. Studying salusin- $\beta$ in overt hypothyroidism may highlight its diagnostic value in this group of patients.

We encourage other research in this area in other population groups to uncover more about the cardiovascular effects of SC hypothyroidism.

\section{CONCLUSION}

The elevated salusin- $\beta$ level supports the opinion that $\mathrm{SC}$ hypothyroidism has a cardiovascular risk and 
may justify treatment of these cases whose TSH $<10$ $\mathrm{mIU} / \mathrm{l}$.

Source of support: this work is self-supported by authors

The study was approved by Zagazig Medical Institutional Review board (IRB\#:6865)

Conflict of interest: no conflict of interest

Financial Disclosure: no financial disclosure REFERENCES

1) Cooper DS, Biondi B. Subclinical thyroid disease. The Lancet. 2012;379(9821):1142-54.

2) Biondi B, Cappola AR, Cooper DS. Subclinical Hypothyroidism: A Review. JAMA. 2019;322(2):15360.

3) Decandia F. Risk factors for cardiovascular disease in subclinical hypothyroidism. Ir J Med Sci 1971. 2018;187(1):39-43.

4) Delitala AP, Fanciulli G, Maioli M, Delitala G. Subclinical hypothyroidism, lipid metabolism and cardiovascular disease. Eur J Intern Med. 2017;38:1724.

5) Goff D C, Lloyd-Jones D M, Bennett G, et al. 2013 ACC/AHA Guideline on the Assessment of Cardiovascular Risk. Circulation. 2014;129(25_suppl_2):S49-S73.

6) Shichiri M, Ishimaru S, Ota T, Nishikawa $T$, Isogai $T$, Hirata Y. Salusins: newly identified bioactive peptides with hemodynamic and mitogenic activities. Nat Med. 2003;9(9):1166-72.

7) Suzuki N, Shichiri M, Tateno T, Sato K, Hirata Y. Distinct systemic distribution of salusin- $\alpha$ and salusin$\beta$ in the rat. Peptides. 2011;32(4):805-10.

8) Saito $T$, Dayanithi G, Saito J, Onaka T, Urabe T, Watanabe TX, et al. Chronic Osmotic Stimuli Increase Salusin- $\beta$-Like Immunoreactivity in the Rat Hypothalamo-Neurohypophyseal System: Possible Involvement of Salusin- $\beta$ on $[\mathrm{Ca} 2+]$ i Increase and Neurohypophyseal Hormone Release from the Axon Terminals. J Neuroendocrinol. 2008;20(2):207-19.

9) Zhou CH, Pan J, Huang H , Zhu Y, Zhang M, Liu L, et al. Salusin- $\beta$ Not Salusin- $\alpha$ Promotes Vascular Inflammation in ApoE-Deficient Mice via the I$\kappa \mathrm{B} \alpha / \mathrm{NF}-\kappa \mathrm{B}$ Pathway. PLoS ONE [serial online]. 2014;9(3). e91468. Accessed December 6, 2020.

10)Izumiyama $H$, Tanaka $H$, Egi $K$, Sunamori $M$, Hirata Y, Shichiri M. Synthetic Salusins as Cardiac Depressors in Rat. Hypertension. 2005;45(3):419-25.

11) Pearce

SHS, Brabant G, Duntas LH, Monzani F, Peeters RP, Ra zvi S, et al. 2013 ETA Guideline: Management of Subclinical Hypothyroidism. Eur Thyroid J. 2013;2(4):215-28.

12)Walsh JP, Bremner AP, Bulsara MK, O'Leary P, Leedman PJ, Feddema P, et al. Subclinical thyroid dysfunction and blood pressure: a community-based study. Clin Endocrinol (Oxf). 2006;65(4):486-91.

13) Åsvold BO, Bjøro T, Vatten LJ. Associations of TSH levels within the reference range with future blood pressure and lipid concentrations: 11-year follow-up of the HUNT study. Eur J Endocrinol. 2013;169(1):7382.

14)Liu XL, He S, Zhang SF, Wang J, Sun XF, Gong $\mathrm{CM}$, et al. Alteration of Lipid Profile in Subclinical Hypothyroidism: A Meta-Analysis. Med Sci Monit Int Med J Exp Clin Res. 2014;20:1432-41.

15)Udovcic M, Pena RH, Patham B, Tabatabai L, Kansara A. Hypothyroidism and the Heart. Methodist DeBakey Cardiovasc J. 2017;13(2):55-9.

16) Rodondi N, Bauer DC, Cappola AR, Cornuz J, Robbins J, Fried LP, et al. Subclinical Thyroid Dysfunction, Cardiac Function and the Risk of Heart Failure: The Cardiovascular Health Study. J Am Coll Cardiol. 2008;52(14):1152-9.

17)Redford $C$ and Vaidya B. Subclinical hypothyroidism: Should we treat? Post Reprod Health. 2017;23(2):5562.

18) Walsh JP, Bremner AP, Bulsara MK, O'Leary P, Leedman PJ, Feddema P, et al. Subclinical Thyroid Dysfunction as a Risk Factor for Cardiovascular Disease. Arch Intern Med. 2005;165(21):2467-72.

19) Razvi S, Weaver JU, Vanderpump MP, Pearce SHS. The Incidence of Ischemic Heart Disease and Mortality in People with Subclinical Hypothyroidism: Reanalysis of the Whickham Survey Cohort. J Clin Endocrinol Metab. 2010;95(4):1734-40.

20)Rodondi N, Elzen WPJ, Bauer DC, Cappola AR, Razvi S, Walsh JP, et al. Subclinical Hypothyroidism and the Risk of Coronary Heart Disease and Mortality. JAMA. 2010;304(12):1365-74.

21) McQuade C, Skugor M, Brennan DM, Hoar B, Stevenson C, Hoogwerf BJ. Hypothyroidism and Moderate Subclinical Hypothyroidism Are Associated with Increased All-Cause Mortality Independent of Coronary Heart Disease Risk Factors: A PreCIS Database Study. Thyroid. 2011;21(8):837-43.

22)Cappola AR, Fried LP, Arnold AM, Danese MD, Kuller LH, Burke GL, et al. Thyroid status, cardiovascular risk, and mortality in older adults. J Am Med Assoc. 2006;295(9):1033-41.

23)Boekholdt SM, Titan SM, Wiersinga WM, Chatterjee $\mathrm{K}$, Basart DCG, Luben R, et al. Initial thyroid status and cardiovascular risk factors: The EPIC-Norfolk prospective population study. Clin Endocrinol (Oxf). 2010;72(3):404-10.

24)Sgarbi JA, Matsumura LK, Kasamatsu TS, Ferreira SR, Maciel RMB. Subclinical thyroid dysfunctions are independent risk factors for mortality in a 7.5-year follow-up: the Japanese-Brazilian thyroid study. Eur J Endocrinol. 2010;162(3):569-77.

25) Watanabe $T$, Sato $K$, Itoh $F$, Iso $Y$, Nagashima $\mathrm{M}$, Hirano $\mathrm{T}$, et al. The roles of salusins in 
atherosclerosis and related cardiovascular diseases. J Am Soc Hypertens. 2011;5(5):359-365.

26) Koya T, Miyazaki T, Watanabe T, Shichiri M, Atsumi $\mathrm{T}$, Kaneyama JK ,et al. Salusin- $\beta$ accelerates inflammatory responses in vascular endothelial cells via NF- $\kappa \mathrm{B}$ signaling in LDL receptor-deficient mice in vivo and HUVECs in vitro. Am J Physiol-Heart Circ Physiol. 2012;303(1):H96-H105.

27) Sato K, Watanabe R, Itoh F, Shichiri M, Watanabe T. Salusins: Potential Use as a Biomarker for Atherosclerotic Cardiovascular Diseases. Int $\mathbf{J}$ Hypertens (online journal). 2013;2013:965140. Accessed October 18, 2020.
28) Wang T, Dong A, Cao H. Serum Salusin- $\beta$ Levels Are Correlated with Slow Coronary Flow. Genet Test Mol Biomark. 2016;20(7):393-7.

29)Akyüz A, Aydın F, Alpsoy Ş, Gür DÖ, Güzel S. Relationship of serum salusin beta levels with coronary slow flow. Anatol J Cardiol. 2019;22(4):17784.

30 ) Atmaca HU, Akbas F. Is salusin -alpha a new marker of cardiovascular disease risk in hypothyroidism ? Acta Endocrinol (Buchar). Jan-Mar 2017;13(1):53-59.

To Cite:

Hassanin, H., Abomandour, H., Hassaneen, A., Farag, A., Sediq, A. Salusin- $\beta$ in patients with subclinical hypothyroidism and low to moderate cardiovascular disease risk. Zagazig University Medical Journal, 2022; (1112-1117): -. doi: 10.21608/zumj.2021.88829.2308 